\title{
Two flares of Still's disease after two doses of the ChAdOx1 vaccine
}

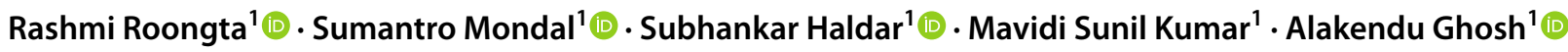

Received: 21 January 2022 / Revised: 28 February 2022 / Accepted: 1 March 2022 / Published online: 6 March 2022

(c) The Author(s), under exclusive licence to International League of Associations for Rheumatology (ILAR) 2022

\begin{abstract}
We report the case of an 18-year-old male with Still's disease for the last 3 years, in remission, who developed two flares of his disease after receiving two doses of the ChAdOX1 nCoV-19 vaccine. While the first flare was mild requiring steroid initiation and resolved rapidly, the second flare after the second dose was much severe, requiring pulse steroid and tocilizumab. We also review three reported cases of flares of Still's disease after COVID-19 vaccination. The temporal association of the flares with both vaccine doses strengthens the association between the vaccine administration and the flare. The proposed mechanism may be due to activation of the innate immune system by the vaccine adjuvants. This review serves to inform the medical community regarding a possible role of the vaccine in producing a systemic inflammatory response. Early detection and treatment can help reduce morbidity in these cases.
\end{abstract}

Keywords AOSD $\cdot$ COVID-19 $\cdot$ Flare $\cdot$ SJIA $\cdot$ Vaccine

\section{Introduction}

With the introduction of the vaccines against coronavirus disease 2019 (COVID-19) in 2020, a massive attempt to vaccinate every individual has been underway. With the large scale vaccination drives being conducted on a global scale, a small fraction of the recipients develops adverse events to it. Medical literature on the adverse events of these vaccines is constantly being updated. These studies not only help us to identify vaccine-induced complications early, but also

The paper has not been submitted to another journal and has not been published in whole or in part elsewhere previously.

Rashmi Roongta

rashmi_rungta@hotmail.com

Sumantro Mondal

drmsumantro@gmail.com

Subhankar Haldar

haldarsskm@gmail.com

Mavidi Sunil Kumar

sunil.4rnz4ever@gmail.com

Alakendu Ghosh

alakendughosh@gmail.com

1 Department of Clinical Immunology and Rheumatology, Institute of Postgraduate Medical Education and Research, 244, A. J. C. Bose Road, Kolkata 700020, West Bengal, India manage them effectively. Vaccine-induced autoimmunity is a known but poorly understood concept. With respect to the COVID-19 vaccine, various reports of vaccine induced autoimmunity have been published [1, 2]. Arthritis, pericarditis, uveitis, immune thrombocytopenia, autoimmune liver diseases, and other autoimmune rheumatic diseases like lupus and rheumatoid arthritis have been reported.

Molecular mimicry and immune cross-reactivity are proposed mechanisms of autoimmunity [3]. In vulnerable settings, exacerbation of the normal immune response of the vaccine to produce a hyper-inflammatory state leads to the autoimmune phenomena. Flare ups of rheumatic diseases after vaccination have also been reported [4, 5]. However, it is difficult to establish whether these events are a chance occurrence or actually related to the vaccine. New onset and flares of Adult Onset Still's Disease (AOSD) post-vaccination have been reported recently. Here, we report the case of a boy with Still's disease who developed two flares after two doses of the ChAdOx nCoV-19 vaccine.

\section{Case report}

We present the case of an 18-year-old male with systemic onset juvenile idiopathic arthritis (sJIA) diagnosed 3 years back. He had been started on steroids and methotrexate at diagnosis. Steroids had been subsequently tapered 
and stopped 2 years back. He had been in remission for 2 years prior to presentation, on only $15 \mathrm{mg}$ methotrexate per week. His blood parameters including a complete blood count, liver enzymes, C-reactive Protein (CRP), and erythrocyte sedimentation rate (ESR) were normal at his last visit in August, 2021.

He had received the first dose of the ChAdOx1 vaccine on 28/08/2021, soon after he had turned 18 years old. One week later, he developed high-grade fever, arthralgia involving both knees, myalgia, and a sore throat. He had no complaints of rash. His clinical examination revealed few subcentimetric cervical lymph nodes. His laboratory workup showed high total counts $(15,000 /$ cumm; neutrophils, $87 \%$ ), high C-reactive protein (CRP) of $78 \mathrm{mg} / \mathrm{L}$ (normal: $<5 \mathrm{mg} / \mathrm{L}$ ), and elevated ferritin levels of 2883 $\mathrm{mcg} / \mathrm{L}$ (normal: $12-300 \mathrm{mcg} / \mathrm{L}$ ) (Fig. 1). Infectious etiologies were ruled out by negative blood and urine cultures and serologies for malaria and dengue. Severe acute respiratory syndrome coronavirus 2 (SARS-CoV-2) reverse transcriptase-polymerase chain reaction (RT-PCR) was also negative. With a possible diagnosis of a flare of his underlying disease, the prednisolone was initiated at a dose of $40 \mathrm{mg} /$ day. His fever and arthralgia resolved within 2 days.

Prednisolone was gradually tapered by $5 \mathrm{mg}$ every week. His parameters showed improvement with fall of total counts to $8500 / \mathrm{cumm}$, ferritin to $250 \mathrm{mcg} / \mathrm{L}$, and CRP to $6 \mathrm{mg} / \mathrm{L}$ on $09 / 29 / 2021$. There was further decline in the inflammatory markers to baseline levels tested in November, 2021.
He received the second dose of the ChAdOx 1 vaccine on 11/29/2021. At that time, he was on $15 \mathrm{mg} /$ week of methotrexate and $7.5 \mathrm{mg} /$ day of oral prednisolone. He was admitted at our department 9 days later with complaints of high-grade fever, sore throat, and pain in bilateral knees and elbows. He also had complaints of dyspnea and pleuritic chest pain with mild hypoxia (room air saturation was 93\%). His clinical examination was significant for tachycardia, pyrexia, tachypnea, and mildly reduced breath sounds at bases of both lung fields. He was again worked up for infections given his recent increase in steroid dose, but his cultures and serologies came back negative. Procalcitonin level was normal. He was tested for COVID-19 again by RT-PCR and tested negative. With a diagnosis of possible flare of Still's disease and prompt response to increment in oral steroid after the first vaccine, his steroid was again increased to $40 \mathrm{mg}$ prednisolone per day. His symptoms improved for 1 day. He developed high-grade fever with throat pain, dyspnea, and myalgia again. His reports showed neutrophilic leucocytosis (20,000/cumm, neutrophils, $92 \%)$, elevated CRP (178 mg/L) and ferritin level $(2400 \mathrm{mcg} / \mathrm{L})$, and high ESR, consistent with flare of systemic onset JIA. Fasting triglyceride levels were $371 \mathrm{mg} / \mathrm{dL}$, and lactate dehydrogenase (LDH) levels were $878 \mathrm{U} / \mathrm{L}$. His interleukin-6 (IL-6) levels were $70 \mathrm{pg} / \mathrm{mL}$ (normal $<7 \mathrm{pg} / \mathrm{mL}$ ), and anti-SARS-CoV-2S antibody titers were $>250 \mathrm{U} / \mathrm{mL}$ (negative value $<0.8 \mathrm{U} / \mathrm{mL}$ ). A chest $\mathrm{X}$-ray was done in view of dyspnea and hypoxia which was apparently normal. A computed tomography (CT) scan of his chest revealed

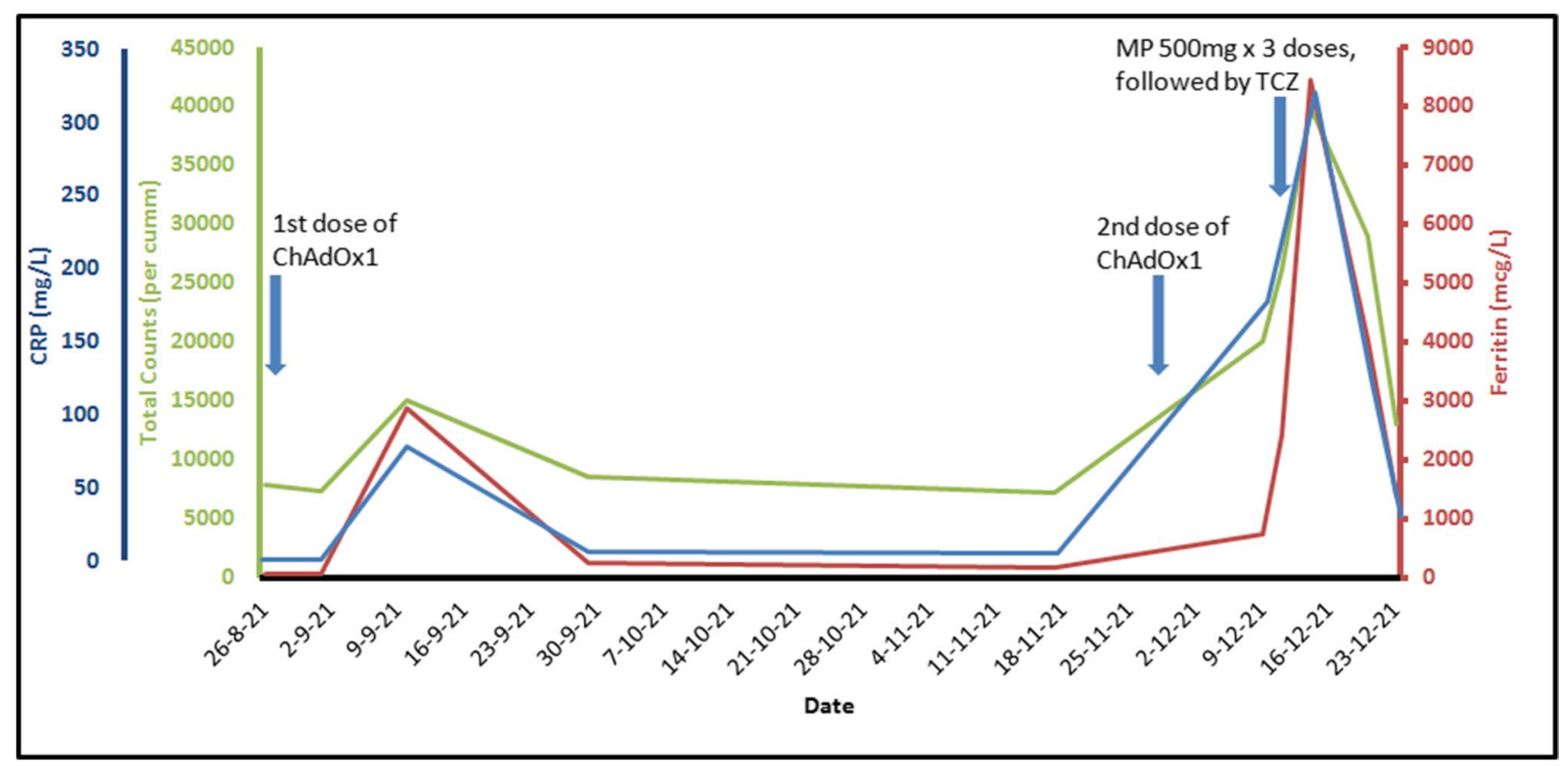

Fig. 1 Temporal correlation of rise in inflammatory markers with the time of vaccine administration. CRP, C-reactive protein; MP, methylprednisolone; TCZ, Tocilizumab 
bilateral pleural effusions. He was pulsed with intravenous methylprednisolone $500 \mathrm{mg}$ per day for 3 days. Due to the severity of his symptoms, he was administered intravenous tocilizumab $(8 \mathrm{mg} / \mathrm{kg})$. He became afebrile after 3 days. His ferritin and CRP showed an increasing trend initially, followed by a gradual decline. He was switched to oral prednisolone and methotrexate was continued. A written consent was obtained from the patient for publication.

\section{Discussion}

The SARS-CoV-2 has been well documented to produce an autoimmune response [6]. Flares of pre-existing autoimmune diseases after COVID vaccines have also been reported $[4,5]$. With respect to the JIA-AOSD spectrum, while most studies report a low incidence of JIA flares after routine vaccinations [7, 8], a few case reports of JIA flares or new onset AOSD after influenza and pneumococcal vaccines exist [9-11]. In a small study, the BNT162b2 mRNA vaccine was well tolerated in 21 JIA patients (none were having sJIA) with no flares [12]. Systemic hyper-inflammation after COVID-19 vaccines has been reported [13, 14]. Although the association between vaccine administration and the systemic flare is still unclear, many plausible explanations have surfaced.

AOSD is a characteristic systemic autoinflammatory disorder which refers to innate immune system hyper-responsiveness. There is macrophage and neutrophil activation to danger signals called pathogen-associated molecular patterns (PAMPs) or danger-associated molecular patterns (DAMPs). These are recognized by the toll-like receptors (TLRs) and nucleotide-binding oligomerization domain receptors (NOD-like receptors) which constitute the pattern recognition receptor (PRR) family. This interaction triggers signal transduction and incites inflammatory responses through NLR pyrin domain containing 3 (NLRP3) inflammosome in patients with genetic susceptibility $[15,16]$. This leads to excessive production of IL- $1 \beta$ and IL- 18 which stimulate immune cell activation and production of IL-6, IL-8, and IL-17 and tumor necrosis factor (TNF) leading to a cytokine storm which is responsible for the symptoms and signs of AOSD [16, 17]. High levels of ferritin, denoting macrophage activation, is seen in AOSD. Deficiency or impairment of regulatory mechanisms like that of natural killer (NK) cells or regulatory $\mathrm{T}$ cells also contributes to its pathogenesis. The cytokine storm is a major pathogenic factor for severe COVID-19. Severe COVID-19 is now hypothesized to be a new member under the umbrella of hyper-ferritinemic syndromes [18]. Higher levels of IL-6 and IL-10 were observed in patients with severe COVID-19 as compared to AOSD, while higher levels of IL-18 (derived from inflammasome activation) were seen in AOSD [19]. The two diseases share many clinical manifestations, and treatment options for both diseases are also similar including steroids and IL-6 inhibition. The exact mechanism by which vaccines induce this autoinflammatory response is not known. However, similar pathogenetic mechanisms may exist.

The spike protein of the SARS-CoV-2 is highly antigenic and can act as a PAMP and activate TLRs 2 and 4 leading to inflammatory responses [20, 21]. Immunogenic vaccine adjuvants are recognized by the endosomal TLRs and other inflammosome components like NOD-2, MDA-5, and RIG-1. This leads to activation of the innate immune system resulting in an inflammatory response mimicking autoinflammatory diseases [22]. The BNT162b2 vaccine has been shown to elicit human antibody and $\mathrm{T}_{\mathrm{H}} 1 \mathrm{~T}$ cell responses with production of Interferon gamma [23]. Under vulnerable circumstances, as in case of immune systems prone to exaggerated immune responses, this might lead to a hyper-immune state. Overactivation of the innate immune responses is also one of the main pathogenetic factors of AOSD [24].

A PubMed and Scopus database search done on $17 / 02 / 2022$ using the keywords ("coronavirus" OR "COVID-19" OR "SARS-CoV-2" OR "coronavirus disease 2019") AND ("vaccine" OR "vaccination") AND ("Still's disease" OR "AOSD” OR "Systemic Onset Juvenile Idiopathic Arthritis") (Fig. 2). The abstracts of all the results were studied, and three reports of AOSD flares after COVID-19 vaccine were identified [25-27] (Table 1). Few cases of new onset AOSD after vaccine were also identified [28-33]. Articles not related to flare of AOSD after a COVID-19 vaccine were excluded. The cases of AOSD flares post-vaccination have been detailed below.

The first case was of a 34-year-old lady with AOSD in low disease activity state on etanercept and low-dose steroid. She flared 7 days after receiving the ChAdOx1 vaccine and had a tumultuous course in the hospital [25]. Her steroid dose was increased from low dose to $20 \mathrm{mg} /$ day and then to $50 \mathrm{mg} /$ day with transient improvement. Due to persistent

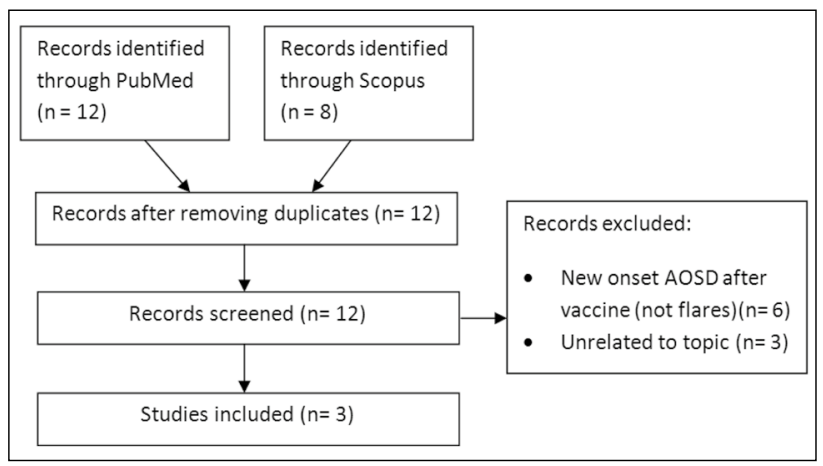

Fig. 2 Flowchart showing process of literature search and selection (AOSD, Adult Onset Still's Disease) 
Table 1 Characteristics of post-vaccine AOSD flare case reports (TCZ, tocilizumab)

\begin{tabular}{|c|c|c|c|c|}
\hline & Current case & Jeon et al. [25] & Yamamoto et al. [26] & Muench et al. [27] \\
\hline Age (years) & 18 & 34 & 37 & 23 \\
\hline Gender & Male & Female & Female & Female \\
\hline $\begin{array}{l}\text { Duration of Still's dis- } \\
\text { ease (in years) }\end{array}$ & 3 & 22 & 13 & Around 1 year \\
\hline $\begin{array}{l}\text { Disease status during vac- } \\
\text { cination }\end{array}$ & Remission for 2 years & Flare free for 14 years & Remission for 2 years & Flare free for 3 months \\
\hline $\begin{array}{l}\text { Medications during vac- } \\
\text { cination }\end{array}$ & Methotrexate $15 \mathrm{mg} /$ week & $\begin{array}{l}\text { Etanercept } 50 \mathrm{mg} / \text { week, } \\
\text { low-dose prednisolone }\end{array}$ & Drug free & $\begin{array}{l}\text { Anakinra } 2 \times 100 \mathrm{mg} / \text { day, } \\
\text { prednisolone } 5 \mathrm{mg} / \text { day }\end{array}$ \\
\hline Type of vaccine & ChAdOx1 & ChAdOx1 & BNT162b2 & BNT162b2 \\
\hline Vaccine dose & Flares after both doses & 1st dose & 2nd dose & 1 st dose \\
\hline $\begin{array}{l}\text { Time between vaccination } \\
\text { and symptom onset }\end{array}$ & $\begin{array}{l}7 \text { days [after } 1 \text { st dose) } \\
9 \text { days (after } 2 \text { nd dose) }\end{array}$ & 9 days & Few days & 6 days \\
\hline Type of flare & Systemic and articular & Systemic and articular & Systemic and articular & $\begin{array}{l}\text { Systemic flare, macrophage } \\
\text { activation syndrome }\end{array}$ \\
\hline Imaging & Bilateral pleural effusion & $\begin{array}{l}\text { Bilateral pleural effusion, } \\
\text { pericaridal effusion }\end{array}$ & - & Pericardial effusion \\
\hline Treatment received & $\begin{array}{l}\text { 1st flare-prednisolone } \\
40 \mathrm{mg} / \text { day } \\
\text { 2nd flare-pulse methyl- } \\
\text { prednisolone (500 mg/ } \\
\text { day for } 3 \text { days), TCZ } \\
8 \mathrm{mg} / \mathrm{kg}\end{array}$ & $\begin{array}{l}\text { Pulse methylprednisolone } \\
\text { [125 mg/day for } 3 \text { days, } \\
\text { etanercept } 50 \mathrm{mg} \mathrm{sc} \text {, } \\
\text { methotrexate } 10 \mathrm{mg} / \text { week } \\
\text { followed by TCZ } 8 \mathrm{mg} / \\
\text { kg every } 2 \text { weeks }\end{array}$ & $\begin{array}{l}\text { Prednisolone } 15 \mathrm{mg} / \\
\text { day, TCZ } 162 \mathrm{mg} \text { every } \\
2 \text { weeks for } 3 \text { doses }\end{array}$ & $\begin{array}{l}\text { Methylprednisolone } \\
250 \mathrm{mg} / \text { day, intravenous } \\
\text { immunoglobulin, Anak- } \\
\text { inra } 3 \times 100 \mathrm{mg} / \text { day, oral } \\
\text { cyclosporine } 200 \mathrm{mg} / \text { day }\end{array}$ \\
\hline
\end{tabular}

fever, rash, pleuritic chest pain, and raised inflammatory markers, she received pulse methylprednisolone $(125 \mathrm{mg} /$ day $\times 3$ days) with etanercept $50 \mathrm{mg}$ subcutaneous injection and oral methotrexate $10 \mathrm{mg} /$ week. Due to persistent fever, rash, and chest pain, she was finally administered tocilizumab with which her symptoms resolved.

The second case of AOSD flare was of a 37-year-old Japanese woman, who had AOSD since 13 years and was in remission for 2 years [26]. She developed fever, rash, sore throat, and arthritis a few days after receiving the second dose of the BNT162b2 vaccine. She required steroids and tocilizumab for symptom resolution.

The third case is the development of macrophage activation syndrome (MAS) in a patient with AOSD [27]. The patient had been recently diagnosed with AOSD and had a flare around 3 months prior to vaccination. She was diagnosed to have MAS based on pancytopenia, elevated ferritin, triglycerides, and a very high $\mathrm{H}$-score. She required pulse steroids, intravenous immunoglobulin, and a higher dose of anakinra along with cyclosporine for disease control.

In the above cases, it was difficult to establish whether the relationship between the vaccine and the flare was casual or causal. In our patient, the consecutive flares following both the doses of the vaccines with a fixed temporal correlation imply a possible causal relationship between vaccine administration and flare. This observation is supported by the other cases of hyper-inflammation seen after the COVID19 vaccines [13]. Multiple cases of new onset AOSD after vaccine also help strengthen the association. The flare after the second vaccine was more severe probably because of the stronger immune response to the second dose. One would expect a shorter time to flare after the second dose of the vaccine as compared to the first dose. This can possibly be explained by the fact that the patient had been on steroids prior to the second dose which led to a delayed response. Severe flare requiring tocilizumab/anakinra in all cases warrants careful monitoring in Still's disease after vaccination.

\section{Conclusion}

This case report highlights the possible etiology of the COVID-19 vaccine in initiating a hyper-immune response. This is to inform the medical community of the possible effect of the vaccine in this population. Close monitoring of such patients and prompt initiation of treatment can help in reducing morbidity. This review serves to sensitize physicians to this possible adverse effect and should in no way deter the vaccination drive which is imperative to control the spread of the pandemic.

Author contribution RR - conception of work, data acquisition, preparing draft

MSK - data acquisition, preparing draft

$\mathrm{SH}$ - Data analysis, revised manuscript 
SM - conception of work, revised manuscript, approved final version

AG - revised manuscript, approved final version

\section{Declarations}

Informed consent Written consent has been obtained from the patient for publication.

Disclosures None.

\section{References}

1. Ishay Y, Kenig A, Tsemach-Toren T, Amer R, Rubin L, Hershkovitz Y et al (2021) Autoimmune phenomena following SARSCoV-2 vaccination. Int Immunopharmacol 99:107970. https://doi. org/10.1016/j.intimp.2021.107970

2. Chen Y, Xu Z, Wang P, Li XM, Shuai ZW, Ye DQ, Pan HF (2021) New-onset autoimmune phenomena post-COVID-19 vaccination. Immunology. https://doi.org/10.1111/imm.13443

3. Segal Y, Shoenfeld Y (2018) Vaccine-induced autoimmunity: the role of molecular mimicry and immune crossreaction. Cell Mol Immunol 15(6):586-594. https://doi.org/10.1038/cmi.2017.151

4. Fan Y, Geng Y, Wang Y, Deng X, Li G, Zhao J et al (2021) Safety and disease flare of autoimmune inflammatory rheumatic diseases: a large real-world survey on inactivated COVID-19 vaccines. Ann Rheum Dis. https://doi.org/10.1136/annrheumdis-2021-221736

5. Watad A, De Marco G, Mahajna H, Druyan A, Eltity M, Hijazi N et al (2021) Immune-mediated disease flares or new-onset disease in 27 subjects following mRNA/DNA SARS-CoV-2 vaccination. Vaccines 9(5):435. https://doi.org/10.3390/vaccines9050435

6. Dotan A, Muller S, Kanduc D, David P, Halpert G, Shoenfeld Y (2021) The SARSCoV-2 as an instrumental trigger of autoimmunity. Autoimmun Rev 20(4):102792. https://doi.org/10.1016/j. autrev.2021.102792

7. Heijstek MW, Kamphuis S, Armbrust W, Swart J, Gorter S, De Vries LD et al (2013) Effects of the live attenuated measlesmumps-rubella booster vaccination on disease activity in patients with juvenile idiopathic arthritis: a randomized trial. JAMA 309(23):2449-2456. https://doi.org/10.1001/jama.2013.6768

8. Alfayadh NM, Gowdie PJ, Akikusa JD, Easton ML, Buttery JP (2020) Vaccinations do not increase arthritis flares in juvenile idiopathic arthritis: a study of the relationship between routine childhood vaccinations on the Australian immunisation schedule and arthritis activity in children with juvenile idiopathic arthritis. Int J Rheumatol 1078914. https://doi.org/10.1155/2020/1078914

9. Korematsu S, Miyahara H, Kawano T, Yamada H, Akiyoshi K, Sato K et al (2009) A relapse of systemic type juvenile idiopathic arthritis after a rubella vaccination in a patient during a long-term remission period. Vaccine 27(37):5041-5042. https://doi.org/10. 1016/j.vaccine.2009.06.052

10. Shimizu M, Ueno K, Yachie A (2012) Relapse of systemic juvenile idiopathic arthritis after influenza vaccination in a patient receiving tocilizumab. Clin Vaccine Immunol 19(10):1700-1702. https://doi.org/10.1128/CVI.00309-12

11. Sato T, Takeo N, Matsuda-Hirose H, Abe K, Nishida H, Hatano Y (2021) Adult-onset Still's disease following pneumococcal vaccination. Eur J Dermatol 31(4):574-576. https://doi.org/10.1684/ ejd.2021.4102

12. Dimopoulou D, Spyridis N, Vartzelis G, Tsolia MN, Maritsi DN (2021) Safety and tolerability of the COVID-19 messenger RNA vaccine in adolescents with juvenile idiopathic arthritis treated with tumor necrosis factor inhibitors. Arthritis Rheumatol. https:// doi.org/10.1002/art.41977

13. Bindoli S, Giollo A, Galozzi P, Doria A, Sfriso P (2022) Hyperinflammation after anti-SARS-CoV-2 mRNA/DNA vaccines successfully treated with anakinra: case series and literature review. Exp Biol Med (Maywood) 153537022110702. https:// doi.org/10.1177/15353702211070290

14. Baicus C, Delcea C, Pinte L, Dan GA (2021) Hyper-inflammation after COVID-19 mRNA vaccination: at the crossroads of multisystem inflammatory disease and adult onset Still's disease. Does terminology matter? Rom J Intern Med. https://doi. org/10.2478/rjim-2021-0035

15. Church LD, Cook GP, McDermott MF (2008) Primer: inflammasomes and interleukin 1beta in inflammatory disorders. Nat Clin Pract Rheumatol 4(1):34-42. https://doi.org/10.1038/ncprh eum0681

16. Jamilloux Y, Gerfaud-Valentin M, Martinon F, Belot A, Henry T, Sève P (2015) Pathogenesis of adult-onset Still's disease: new insights from the juvenile counterpart. Immunol Res 61(12):53-62. https://doi.org/10.1007/s12026-014-8561-9

17. Mitrovic S, Fautrel B (2018) new markers for adult-onset Still's disease. Joint Bone Spine 85(3):285-293. https://doi.org/10. 1016/j.jbspin.2017.05.011

18 Ruscitti P, Berardicurti O, Di Benedetto P, Cipriani P, Iagnocco A, Shoenfeld Y, Giacomelli R (2020) Severe COVID-19, another piece in the puzzle of the hyperferritinemic syndrome. An immunomodulatory perspective to alleviate the storm. Front Immunol 11:1130. https://doi.org/10.3389/fimmu.2020.01130

19. Meng J, Ma Y, Jia J et al (2021) Cytokine storm in coronavirus disease 2019 and adult-onset still's disease: similarities and differences. Front Immunol 11:603389. https://doi.org/10.3389/ fimmu.2020.603389

20. Pino P, Kint J, Kiseljak D, Agnolon V, Corradin G, Kajava AV et al (2020) Trimeric SARS-CoV-2 spike proteins produced from $\mathrm{CHO}$ cells in bioreactors are high-quality antigens. Process 8(12):1539. https://doi.org/10.3390/pr8121539

21 Zhao Y, Kuang M, Li J, Zhu L, Jia Z, Guo X et al (2021) (2021) SARS-CoV-2 spike protein interacts with and activates TLR41. Cell Res 31(7):818-20. https://doi.org/10.1038/ s41422-021-00495-9

22. Teijaro JR, Farber DL (2021) COVID-19 vaccines: modes of immune activation and future challenges. Nat Rev Immunol 21(4):195-197. https://doi.org/10.1038/s41577-021-00526-x

23. Sahin U, Muik A, Derhovanessian E, Vogler I, Kranz LM, Vormehr M et al (2020) COVID-19 vaccine BNT162b1 elicits human antibody and TH1 T cell responses. Nature 586(7830):594-599. https://doi.org/10.1038/ s41586-020-2814-7

24. Feist E, Mitrovic S, Fautrel B (2018) Mechanisms, biomarkers and targets for adult onset Still's disease. Nat Rev Rheumatol 14(10):603-618. https://doi.org/10.1038/s41584-018-0081-x

25. Jeon YH, Lim DH, Choi SW, Choi SJ (2021) A flare of Still's disease following COVID-19 vaccination in a 34-year-old patient. Rheumatol Int 1-6. https://doi.org/10.1007/s00296-021-05052-6

26. Yamamoto S, Nishimura K, Yo K, Waki D, Murabe H, Yokota $\mathrm{T}$ (2021) Flare-up of adult-onset Still's disease after receiving a second dose of BNT162b2 COVID-19 mRNA vaccine. Clin Exp Rheumatol 39(5):139-140

27. Muench F, Krusche M, Sander LE, Rose T, Burmester G-R, Schneider U (2021) Macrophage activation syndrome in a patient with adult-onset Still's disease following first COVID-19 vaccination with BNT162b2. BMC Rheumatol 5(1):60. https://doi.org/10. 1186/s41927-021-00237-9

28. Park SY, Lee K-H (2021) Adult-onset Still's disease after BNT162b2 mRNA COVID-19 Vaccine. J Korean Med Sci 36(50). https://doi.org/10.3346/jkms.2021.36.e344 
29. Sweeney A, Tracey G, Garnham K (2021) Adult-onset Still disease post-adenovirus vector COVID-19 vaccine. Intern Med J 51(12):2144-2145. https://doi.org/10.1111/imj.15563

30. Leone F, Cerasuolo PG, Bosello SL, Verardi L, Fiori E, Cocciolillo F et al (2021) Adult-onset Still's disease following COVID19 vaccination. Lancet Rheumatol 3(10):e678-e680. https://doi. org/10.1016/S2665-9913(21)00218-6

31. Sharabi A, Shiber S, Molad Y (2021) Adult-onset Still's disease following mRNA COVID-19 vaccination. Clin Immunol 233. https://doi.org/10.1016/j.clim.2021.108878

32. Magliulo D, Narayan S, Ue F, Boulougoura A, Badlissi F (2021) Adult-onset Still's disease after mRNA COVID-19 vaccine. Lancet Rheumatol 3(10):e680. https://doi.org/10.1016/S26659913(21)00219-8
33. Padiyar S, Kamath N, Mathew J, Chandu AS, Deodhar D, Shastry BA, Shashikala T, Ganapati A (2022) New-onset adult-onset Still's disease-like syndrome after ChAdOx $1 \mathrm{nCoV}-19$ vaccination-a case series with review of literature. Clin Rheumatol 1-7. https://doi.org/10.1007/s10067-022-06065-7

Publisher's note Springer Nature remains neutral with regard to jurisdictional claims in published maps and institutional affiliations. 